\title{
An innovative approach to forest fires detection and monitoring: the EU-FIRE project
}

\author{
D. X. Viegas ${ }^{1}$, L. P. Pita ${ }^{1}$, K. Haddad ${ }^{2}$, C. Calisti Tassini ${ }^{3}$, \\ A. Gemelli ${ }^{3}$, V. Quaranta ${ }^{4}$, I. Dimino ${ }^{4} \&$ H. Tsangaris ${ }^{5}$ \\ ${ }^{1}$ Association for the Development of Industrial Aerodynamics, Portugal \\ ${ }^{2}$ Bruel\&Kjoer, Denmark \\ ${ }^{3}$ D'Appolonia S.p.A., Italy \\ ${ }^{4}$ Italian Aerospace Research Centre, Italy \\ ${ }^{5}$ University of Cyprus, Cyprus
}

\begin{abstract}
The EU-FIRE project has the objective of designing a new forest fire monitoring system able to guarantee accurate and continuous surveillance and forecasting, immediate detection of fire beginnings, monitoring of the fire's evolution, and timely exchange of information from fire fronts. The main technological gaps are filled by the integration of optoelectronic and acoustic technologies. The EU-FIRE integrated prototype is based on: (a) A completely new acoustic system for volumetric scanning, based on high directional arrays of microphones, contributing to give a deeper monitoring of forest safety through the possibility of detecting and tracking fires from the beginning by the recognition of their acoustic emission spectrum (i.e. their "sound/noise"). (b) A completely new design of fibre optic sensor networks for temperature and gaseous emissions monitoring installed in grids around sensible infrastructures to provide information on fire movements. Data from fibre optic sensors is collected through new optoelectronic reading units. (c) A completely new acquisition unit for data fusion from both innovative and traditional systems. The project activities covered the characterization of fires' acoustic signature and heat transfer related to fire spread and environmental conditions, type and quantity of material in combustion, background noise, topography, and distance from the source. To achieve these goals, several field tests were performed in 2007 and 2008 - indoor tables and outdoor plots have been burned with different fuels (straw, shrubs, login slash, and pine needles) and environmental conditions. Data have been collected using standard instrumentation consisting of microphones, 2-D and 3-D microphone arrays and fibre optic temperature sensors. Data post processing drove the design of the system in terms of microphones and arrays of numbers and positions, temperature fibre optic sensor installation constraints, etc.
\end{abstract}

Keywords: forest fires, acoustic sensors, fibre optic sensors. 


\section{Introduction}

Forest fires represent a constant threat to ecological systems, infrastructure and human lives. Forest fire fighting is a very dangerous activity that involves extensive human resources with many casualties every year. Apart from preventative measures, early detection and accurate monitoring remain the most effective ways of improving the effects of extinguishing operations, to increase the probability of fire confinement, and thus to reduce damage to people and goods and also costs for emergency management. Although in the last few years many new technologies have been developed and tested (see, for example, Reusen et al. [1] and Fernandez-Berni et al. [2]), nowadays, automatic monitoring is essentially based on thermal and infrared cameras and on remote sensing (Radke et al. [3]) - none of which can ensure large scale and continuous monitoring at affordable costs. As a matter of fact, the arrangement of several cameras to drive and acquire with continuity is an expensive solution in terms of maintenance, operation and installation costs, and, above all, in wooded and thickly vegetated areas where the optical visibility is strongly limited. These types of sensors can also be displaced in aerial platforms (manned or remotely controlled aircraft). Even though there are advantages of ability and territory coverage, these sensors have significant limits of temporal continuity detection and degraded visibility of fire front. Sensors transported in satellites can provide a very wide picture of the monitored area. This makes them effective for detecting fires in remote, unpopulated regions where conventional fire monitoring is less intensive. Thick smoke plumes from forest fires, often extending several hundred kilometres, can also be identified by means of satellite imagery. On the other hand, this technology cannot detect fires through thick clouds, so the total area of the satellite hotspots can represent only a certain percentage of the actual burned area. The time lapse between retrieving and distributing the daily fire images may also be very high, thus leading to a temporal resolution of these systems that is not satisfactory for forest fire management purposes and fire tactical operations. Fires can also be missed if they are not active during the time of satellite overpass or if they are small, of low intensity, or burning on the surface under the tree canopy. The most promising technology is certainly represented by wireless sensors (Hefeeda [4]), at least those cheap enough to be displaced in large networks. However, they have a strong limitation of power supply - having to provide them with batteries means displacing chemical (pollutant) elements in forest areas, with possible dangers to people and animals.

\section{An innovative fire monitoring system: the EU-FIRE project}

A novel large scale forest fire long-term monitoring system is actually being developed in the EU-FIRE project. It is a research and technical development (RTD) project financed by the EC for Environmental Risk Management. The system will overcome the current limits through the exploitation of acoustic and optoelectronic technologies. It consists (EU-FIRE Consortium [5]) of: 
- A new design of acoustic system for volumetric scanning, consisting of a signal processing unit and one or more microphone arrays;

- A new design of fibre optic sensor networks and optoelectronic piloting units for the detection of changes in fire associated parameters, such as temperature and gaseous emission;

- A new control unit for data collection from sensor units as well as from traditional sensors, such as cameras and meteorological stations.

Acoustic sensors will be primarily used to detect fire noise from the very beginning. Thanks to its high range and the fact that it does not need direct visibility, the acoustic system will be installed to continuously perform volumetric scanning in the monitored area. Once an acoustic source is detected in a particular direction, a pattern recognition algorithm is implemented in order to assess if it is a fire or not.

On the contrary, fibre optic sensors are not power supplied - they do not need any maintenance and can therefore be installed in the very heart of the forest, kilometres away from the reading unit. Although they can detect a fire only when it is very near (within a few meters), they can be very useful during an emergency to get information about the real time fire behaviour. Thanks to their flexibility they can be installed around sensible structures (e.g. roads), in concentric circles of about 100 to 500 meters, to provide information as to whether they are at risk and to calculate the actual rate of spread, as shown in Figure 1.

Before designing the system, it was necessary to characterize a forest fire event. A fire is the process of combustion in which a combustible material with an adequate supply of oxygen is subject to enough heat. Thus, three components are required for this process to start: (1) a source of ignition (e.g. heat), (2) oxygen, and (3) fuel. Forest fire fuels can be of different kinds including herbaceous (plants that have leaves and non-woody stems that die at the end of the growing season to the soil level in temperate zones), litter (the top layer of the forest floor consisting of loose organic materials and fallen trees and plants elements), slash (debris left as a result of natural events, such as wind, snow breakage, forest and other vegetation being altered by forestry practices and other land human activities, such as thinning and pruning, road construction, seismic line cleaning), and shrubs (low woody plants distinguished from a tree by their multiple and permanent stems growing from a common base and lower height). It is only in special conditions that fires actually burn heavy biomass as crown fires. As this condition takes some time to be attained, this kind of fuel was not of great concern for the project. From the acoustic and optoelectronic points of view, it was necessary to:

- Evaluate fire radiated heat to fibre optic sensors with cables in the open air, buried or inside the flames, to characterize sensors' resistance when caught in a fire;

- Estimate microphone array detection capabilities in terms of (a) distance from the microphone array by measuring noise at different distances and deriving a law of decrease of the fire noise amplitude, (b) pattern recognition or signature recognition of the fire noise, and (c) the 
estimation of typical forest background noise by measuring noises from different sources that are common in a forest over a long observation time.

To this aim, two experimental campaigns of acoustic and thermal measurements have been carried out in Portugal. Laboratory tests and field tests were executed in March 2007 and April 2008. The former campaign was performed at the LEIF (Laboratory for Forest Fire Studies, an infrastructure created by ADAI to support experimental research on forest fires in Portugal) in Lousã (Coimbra, Portugal), while the latter at Lousã Airfield, close to the laboratory and on Gestosa Mountains.

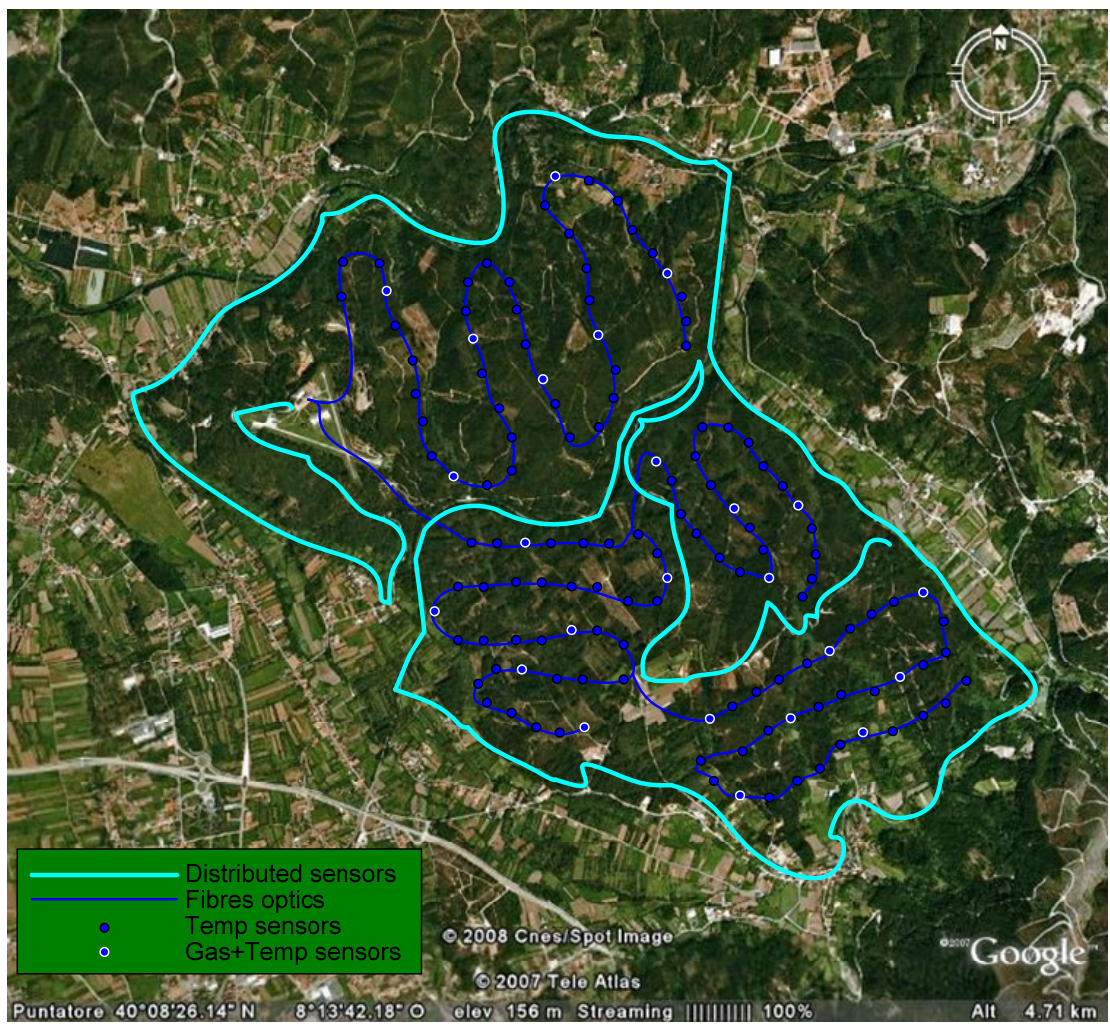

Figure 1: $\quad$ Fibre optic sensor networks deployment.

\section{Acoustic characterization of a fire}

Noise generated by a combustion process of a $1 \mathrm{~m}^{3}$ wooded and brush material in free turbulence regime is mainly due to the shedding of vortex structures of the burnt areas at the base of the fire. These structures have been studied extensively (Detriche and Lanore [6]) and have been shown to be periodic with a frequency inversely related to the square root of the circumference of the burning fuel 
surface, covering the spectrum from about $1.0 \mathrm{~Hz}$ to $100 \mathrm{~Hz}$ as the effective diameter decreases from 2.0 to $0.02 \mathrm{~m}$. It is well known in literature that this part of the noise is very dependent on the size of the fire, type and state of fuel, and weather conditions. Another important aspect is related to the analysis of the time signal representing the pressure variations produced by the fire. Some specific events, called Acoustic Emissions (Wadley and Simmons [7]), can be found due to the microscopic change in stress generated by heat and temperature gradient, which provoke mechanical modifications of the material. These events produce distinct acoustic pulses. If they repeat at a high frequency, as in the case of a great amount of burning fuel, crackling occurs.

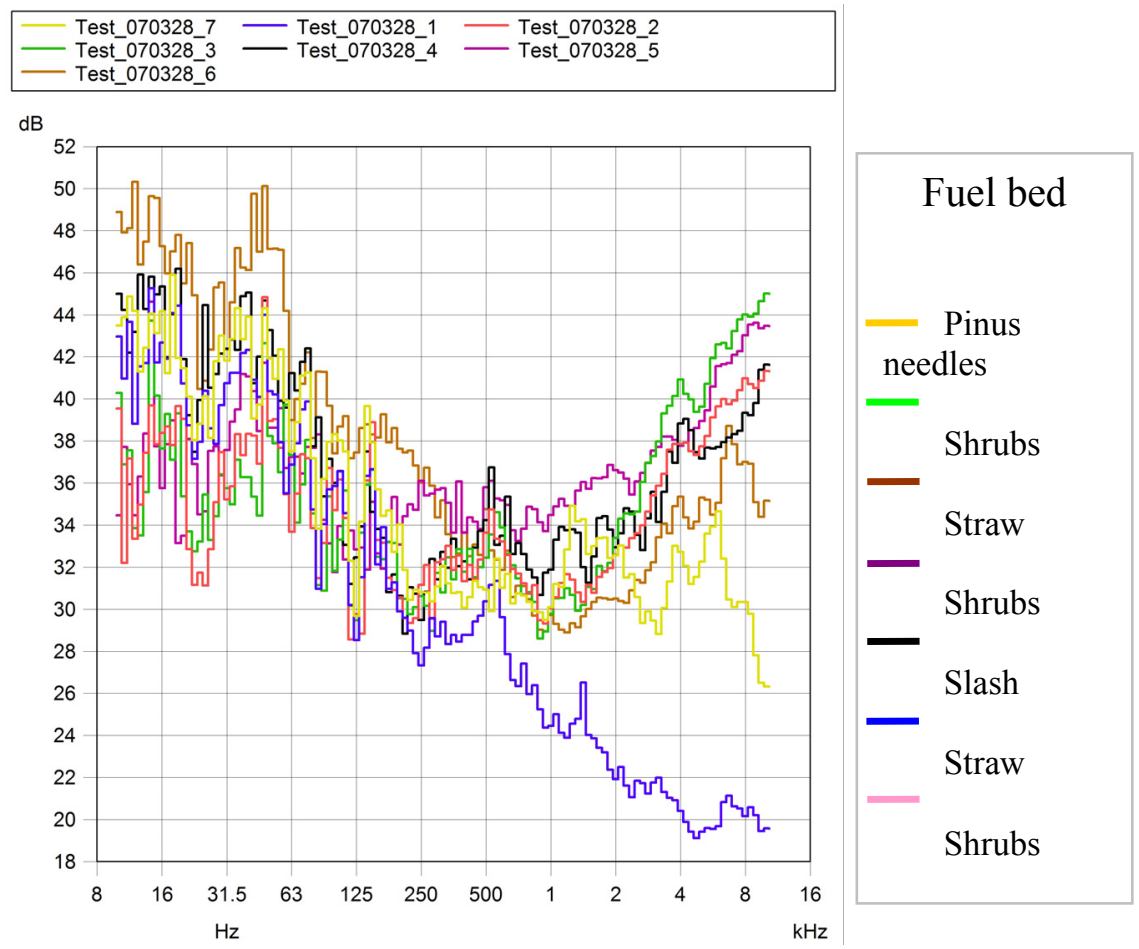

Figure 2: $\quad$ Acoustic spectrum in laboratory test.

The laboratory is equipped with several devices that are used to study, under controlled conditions, the main factors that can affect fire behaviour. The acoustic measurements have been executed with a pressure-field microphone (located two meters from the fire) and a digital tape recorder. For each test a time history of 10 seconds has been extracted. Each signal has been filtered (eighth order band-pass filters with Butterworth characteristic in the frequency range $10 \mathrm{~Hz}-10 \mathrm{kHz}$, see Oppenheim and Shafer [8]) and acoustic features with constant percentage bandwidth technique have been extracted. The noise measurements have been analyzed for each different type of vegetation. The acoustic spectra, 
represented in 1/12 octave band, obtained for the different types of vegetation are reported in Figure 2.

Data analysis demonstrated the high level of the fire noise emissions in the low frequency range $(0-500 \mathrm{~Hz})$ for all the vegetation tested. A significant level of noise in the high frequency range $(1-10 \mathrm{kHz})$ was observed only for the shrub cases. This is due to the crackling that, like impulses in time domain, has a wide frequency band of emission. These results confirm the main spectrum features previously described and available in literature.

\begin{tabular}{|ll|}
\hline Test_070329_1_0m & - Test_070329_2_0m \\
Test_070329_3_0m & Test_070329_4_0m \\
Test_070329_5_0m & - Test_070329_6_0m \\
\hline
\end{tabular}

$\mathrm{dB}$
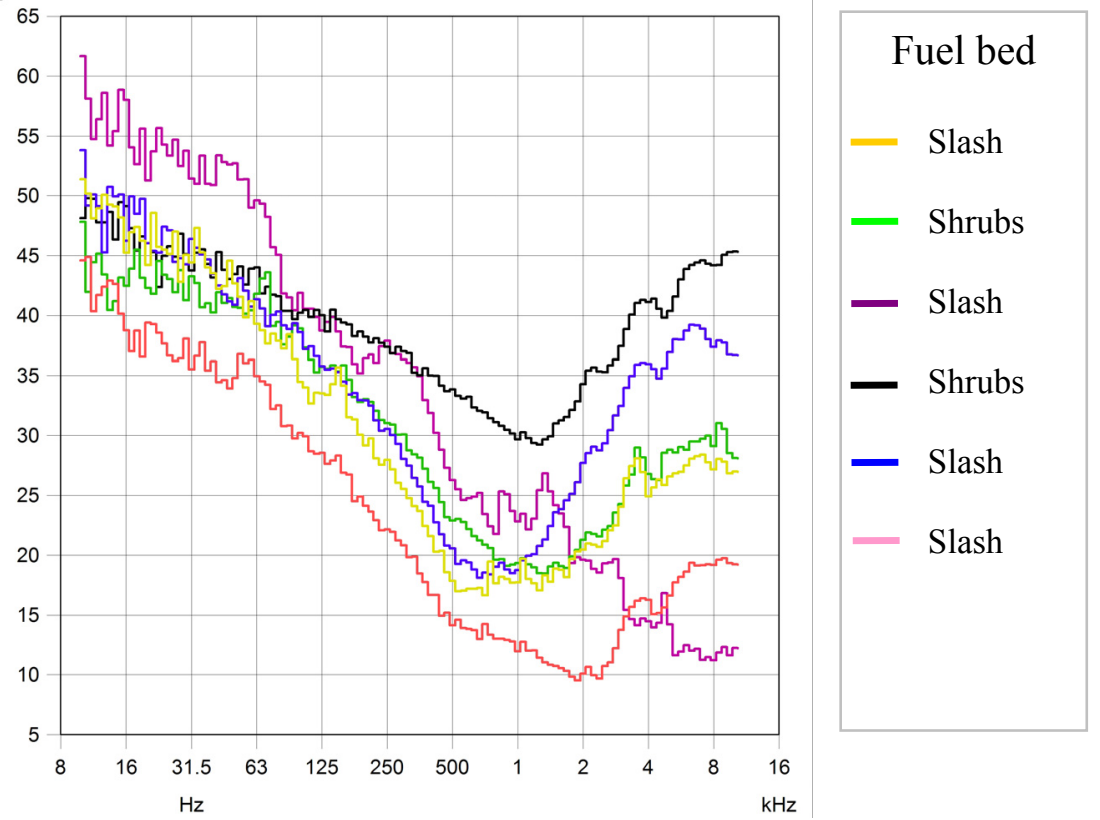

Figure 3: Acoustic spectrum in field test.

A similar setup has been used for outside measurements. For all noise measurements, and for each type of vegetation, data analysis again demonstrated (Figure 3) high levels of fire noise emissions in the low frequency range (0 -500 $\mathrm{Hz}$ ) and the same decay rate up to approximately $1 \mathrm{kHz}$. In this case, an important level of noise emission at high frequency range $(1-10 \mathrm{KHz})$ was observed for different trials. This is due to the contribution of the shrubs always contained in the fire plots.

A differentiation of the fire noise from other types of noise has been performed through the frequency representation. Spectrum evaluation was made before the fire (just before the fire was started), during the fire, and after the fire (just after the fire died). The results obtained for the login slash and straw fuels 


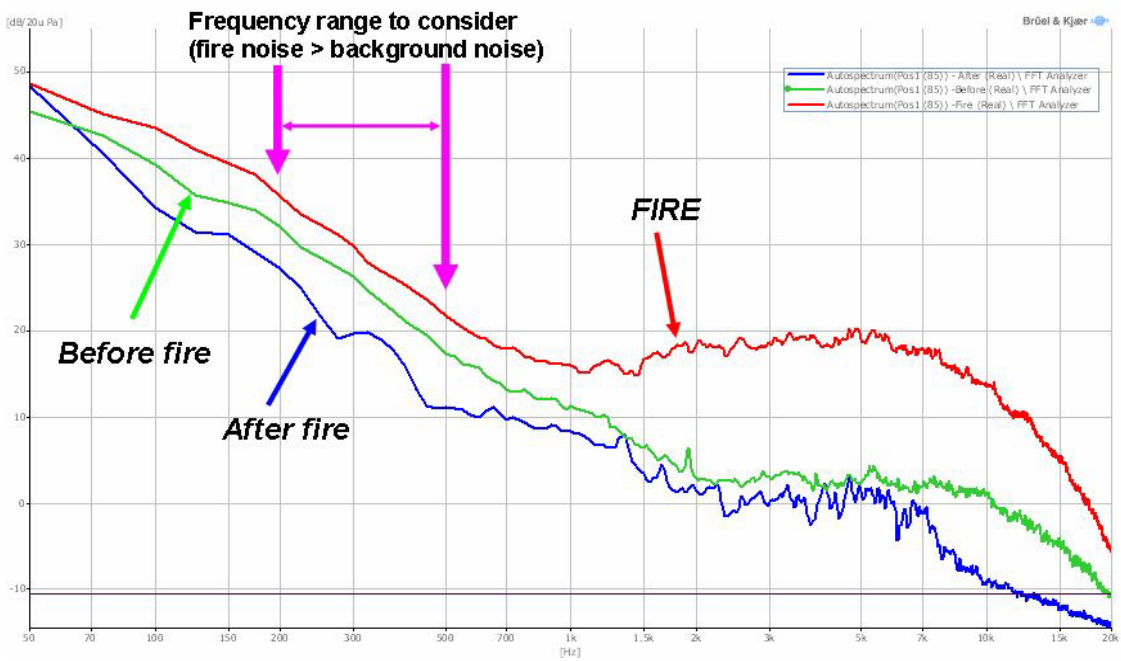

Figure 4: $\quad$ Fire vs. background noise (mic. at $50 \mathrm{~m}$, fuel: login slash).

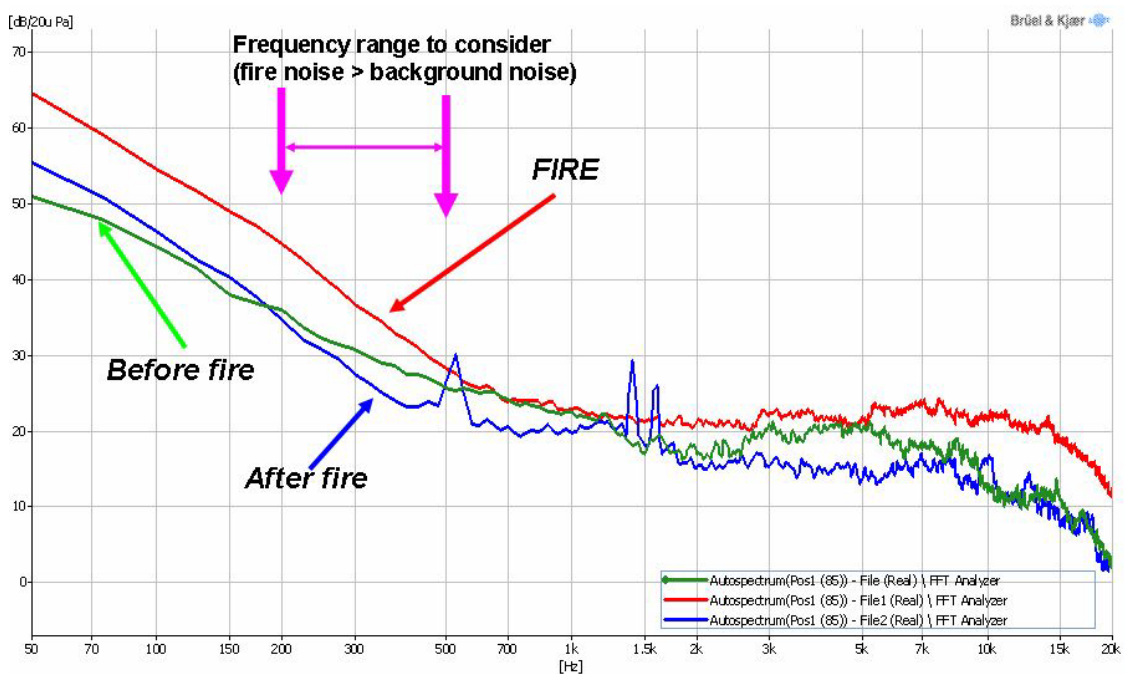

Figure 5: $\quad$ Fire vs. background noise (mic. at $10 \mathrm{~m}$, fuel: straw).

cases are reported in Figures 4 and 5. For all other tested fuels, it has been noticed that in low frequencies (i.e. between 200 and $500 \mathrm{~Hz}$ ) the spectrum recorded during the fire is always higher than the spectrum of the background noise before and after the fire. Thus, the acoustic contribution of the fire is mainly concentrated in this frequency range and it contributes more than the background noise. In presence of background noise with a high frequency level, the fire noise could be masked (important wind speed, human activities, etc.) - 


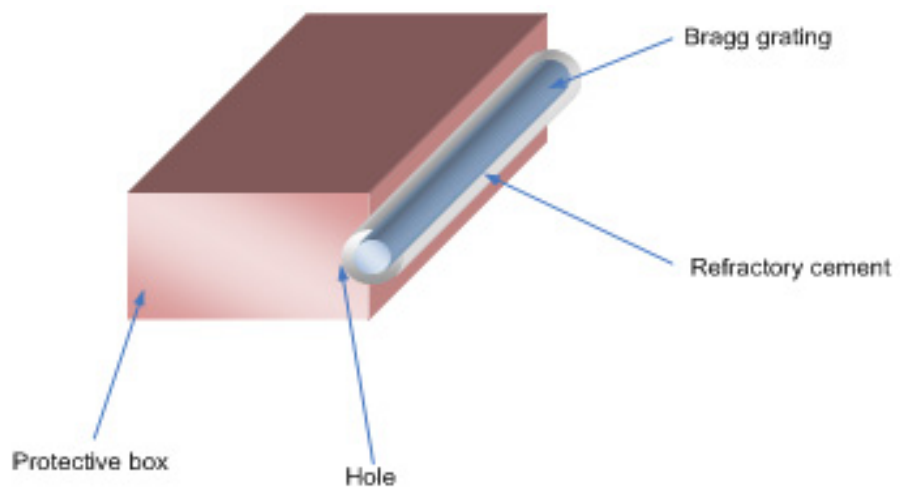

Figure 6: $\quad$ FBG temperature sensor.

the combination of the signal filtering (on the frequency range 200-500 Hz, for instance), the spatial filtering (beamforming) and the pattern recognition would give a better detection and recognition of the fire.

\section{Thermal characterization of a fire}

As for the fibre optic sensors, Fibre Bragg Gratings (FBG) have been used (Othonos et al. [9]). FBG were bounded to a metallic structure parallel to one side of the burning plots and 0.5 meters far, with standard thermocouples used to provide reference temperature variation. Sand tables have also been used, with sensors buried at $4 \mathrm{~cm}$ depth.

The results obtained demonstrated that temperature profiles are characterized by high temperatures $\left(>1000^{\circ} \mathrm{C}\right)$ reached in a small amount of time (i.e. very high temperature gradients, if measured by a FBG in direct contact or very near, one meter at the maximum, to the fire). The effects of fires appear less important when the fibre optic cable is buried. This means that sensors have to be leant on the ground but have to be protected somehow from high temperatures, as FBG should remain operative even in contact with the fire. A protective case has therefore been designed and developed in order to ensure:

- An instantaneous heat transmission from the external side of the coverage to the FBG;

- A temperature attenuation such to respect the maximum operating temperature of an $\mathrm{FBG}$ (around $80-85^{\circ} \mathrm{C}$ ).

The physical parameters of the case have been optimised by means of a simulation tool. The first prototype is shown in Figure 6 and it is now under patenting.

\section{Conclusions}

Following field testing results, the EU-FIRE system has finally been designed. Taking into account a reference scenario in the mountains around Lousã Airfield, the system will consist of (Figure 7): 


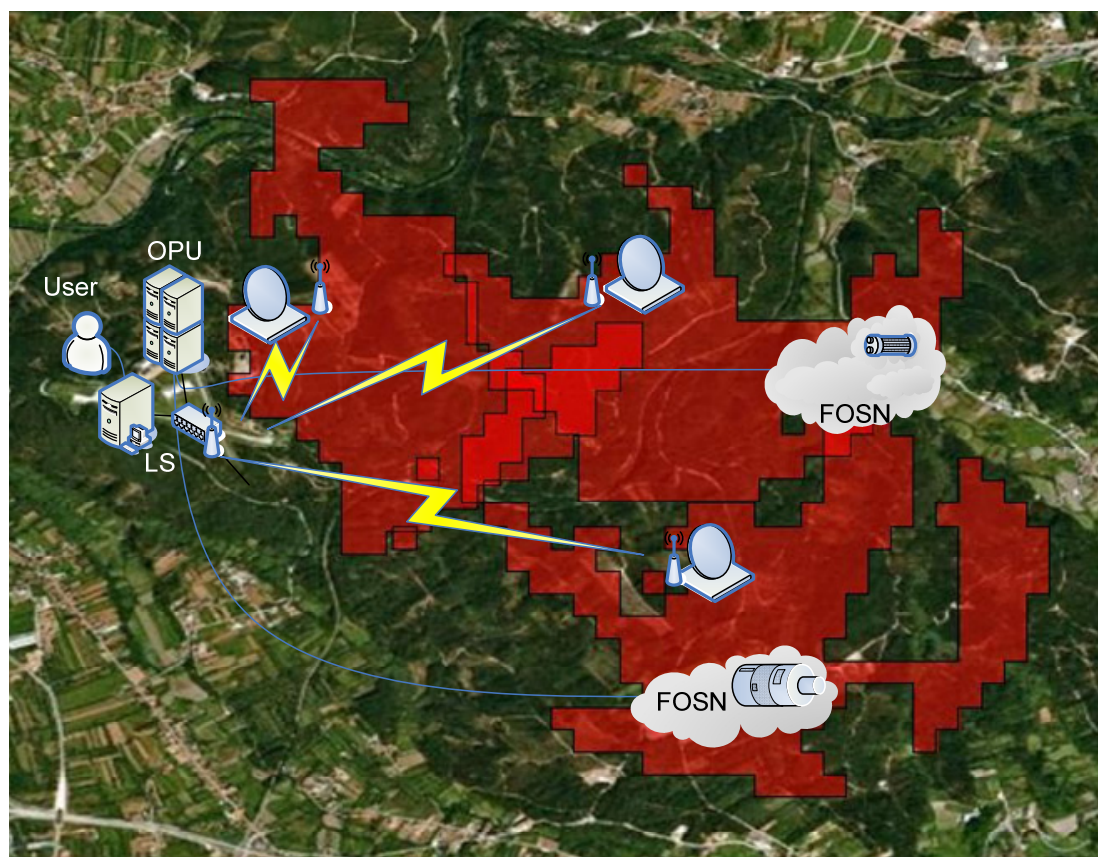

Figure 7: $\quad$ Lousã airfield scenario.

- 2 microphone arrays, ensuring a good coverage in the monitored area;

- 135 FBG sensors, displaced on a grid of maximum 250 meters spacing;

- 50 gas sensors for the detection of methane, according to Beer-Lambert law (Mazotti et al. [10]);

- $\quad 75 \mathrm{~km}$ of fibre optic cables for temperature monitoring by means of distributed sensing commercial devices (Thenevaz et al. [11]).

A simulation platform has been developed in a Labview environment in order to evaluate system performances. It shows that such reference system configuration has a 67 percent chance to detect fire noise at $1 \mathrm{~km}$ within 10 minutes and with a confirmation within 5 minutes. The performance can be increased up to the 95 percent by improving the training of the pattern recognition module. The EU-FIRE prototype will be extensively tested in May 2009. Updated data will be presented during the conference.

\section{References}

[1] Reusen I. et al., Near-real-time forest fires monitoring system: case study with a manned aerial vehicle within the OSIRIS project, Modelling, Monitoring and Management of Forest Fires Ed. WIT Press, 2008.

[2] Fernandez-Berni J. et al., A vision-based monitoring system for very early automatic detection of forest fires, Modelling, Monitoring and Management of Forest Fires Ed. WIT Press, 2008. 
[3] Radke L., Hegg A. et al., Airborne Measurements on smoke from biomass burning, 411-4222, 1988.

[4] Hefeeda M., Forest Fire Modelling and Early Detection using Wireless Sensor Networks, Technical Report TR 2007-08, School of Computing Science, Simon Fraser University, August 2007.

[5] EU-FIRE Consortium, First Year Publishable Report, Doc. No. Deliverable D6, Iss. 2.0, 2008 (available from www.eufire.org)

[6] Detriche P. and Lanore J.C., An Acoustic Study of Pulsation Characteristics of Fires, Fire Technology, 16, 204, 1980.

[7] Wadley H. N. G. and Simmons J. A., Microscopic Origins of Acoustic Emission, ASNT Handbook on Acoustic Emission, NDT Handbook, Vol. 5, Section 3, Ed. P.M. McIntyre, 1987.

[8] Oppenheim A., Shafer R., Discrete-time Signal Processing, Prentice Hall, Englewood Cliff, NJ., 1989.

[9] Othonos A. et al., Fibre Bragg Gratings, Fundamentals and Applications in Telecommunications and Sensing, Artech house Publishers, 1999.

[10] Mazotti D. et al., High sensitivity Spectroscopy of CO2 around $4.25 \mu \mathrm{m}$ with difference frequency generation, Optics and Lasers in Engineering, Vol. 37, July 2001.

[11] Thenevaz L. et al., Truly distributed strain and temperature sensing using embedded optical fibres, SPIE Proceedings, Vol. 3330, 1998 